\title{
Effects of Stair Case on the Damages Limitation Requirements According Eurocode 8
}

\author{
Altin Seranaj ${ }^{1}$, Agim Seranaj ${ }^{2}$, and Luan Murtaj ${ }^{3}$
}

\begin{abstract}
This study presents an analytical assessment for the influence of the stair cases on low-rise flexible structures performance under the earthquake actions. In design practices of buildings, the stair model is generally not included in the analysis of $\mathrm{RC}$ frame buildings. Due to the rigidity of inclined slab and of short columns around staircase, beams and columns are often characterized by a high seismic demand. Two typologies of reinforced concrete are analysed: First, the reinforced concrete frame constructed with flat beams. The typology is known as frame with "embedded beam in the slab", with a total height $25 \mathrm{~cm}$. Many similar structures have been constructed all around Balkans regions and Middle East. Second, reinforced concrete frames with normal depth of the beams $60 \mathrm{~cm}$ depth. The response of the frames is analysed in both cases: with and without staircases. This is done for a 3and 5 floors building. The effect of infill masonry hallow clay bricks is also considered.

The criterions of comparisons are based on Eurocode 8(2004) and especially on damage limitation states. This investigation is made by using software ETABS. The investigation as was expected show that the staircases are influencing the response of buildings. Their influence is bigger in case that they are distanced from the centre of masses.
\end{abstract}

Keywords-damages limitation, r/c frame, stair modelling, Eurocode.

\section{INTRODUCTION}

$\mathrm{S}$ UBSTANTIAL research efforts have been devoted to investigating the performance of engineering structures during earthquakes such as reinforced concrete buildings, minarets, masonry and wooden buildings. It was reported that hundreds of thousands of buildings suffered different types of damage during these earthquakes. [1]

In the last decades, huge numbers of the reinforced concrete structures are constructed using beams inside reinforced concrete slabs made will hallow clay/concrete/polymers block. However, in most cases, due to lack of deep strong beams, which can form with columns strong frame actions, the resulted transverse stiffness will be low. In modelling and analyzing process the effect of staircases is often neglected. This neglect can be accepted in special cases (when they are positioned in the middle of the structures), in general they have to be considered, especially in frames with embedded beams.

\footnotetext{
${ }^{1}$ Department of Building Construction and Transportation Infrastructure, Polytechnic University of Tirana

${ }^{2}$ Department of Structural Mechanics, Civil Engineering Faculty, Polytechnic University of Tirana, Albania

${ }^{3}$ Department of Structural Mechanics, Civil Engineering Faculty, Polytechnic University of Tirana, Albania
}

This study presents an analytical assessment for the influence of the stair cases on low-rise flexible structures performance under the earthquake actions. The reinforced concrete frames constructed with flat beams of these typologies in Albania are shown on Figure 1.
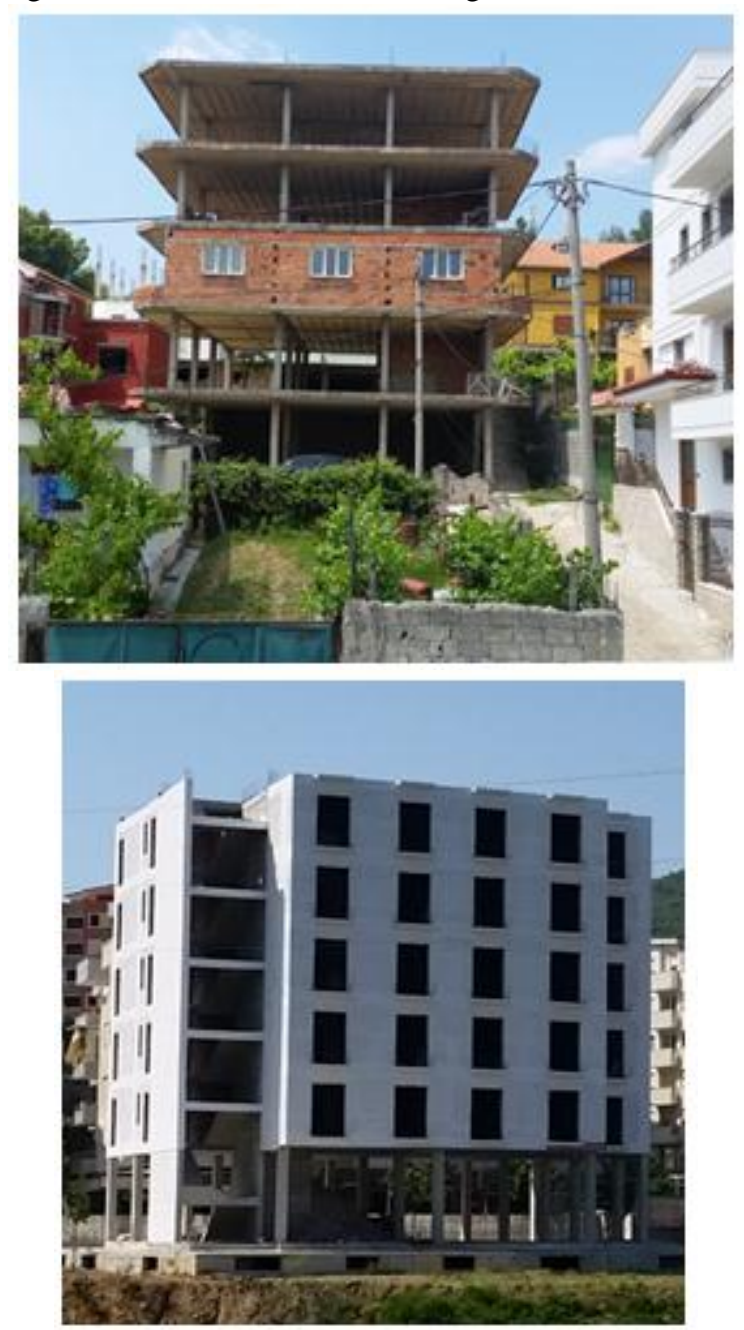

Fig. 1: Reinforced concrete frame structure with embedded beams into the slab

Linear analysis is performed for determination of the influence of stairs under earthquake induced forces.

\section{DESCRIPTION OF THE BUILDINGS}

The investigated buildings are 3 and 5 floors multi-storey reinforced concrete structure with beams depth $25 \mathrm{~cm}$ embedded on slabs. For the normal frame the beams have the 
high $60 \mathrm{~cm}$. The elevation of the building and the floor plan are shown in Figure 2 and Figure 3. The ground floor is $4.2 \mathrm{~m}$ height and for other story height is $3.15 \mathrm{~m}$. The total height of the building above the basement is $10.5 \mathrm{~m}$ for the structure with 3 floors and $16.8 \mathrm{~m}$ for the structure with 5 floors. The dimensions in plane are the same for both buildings $13.8 \times 10.4 \mathrm{~m}$. Another model for the 5 floor building is constructed, with the plane dimensions $13.8 \times 20.8 \mathrm{~m}$, for analysing the influence of the stairs with different plane dimensions of building.

Footings with tie beams represent the foundation. Concrete $\mathrm{C} 25 / 30$ is used. The corresponding modulus of elasticity amounts to $\mathrm{Ecm}=31 \mathrm{GPa}(\mathrm{EN} 1992 /$ Table 3.1). Steel S500 Class $\mathrm{C}$ is used. The structure will be designed for ductility class DCM.

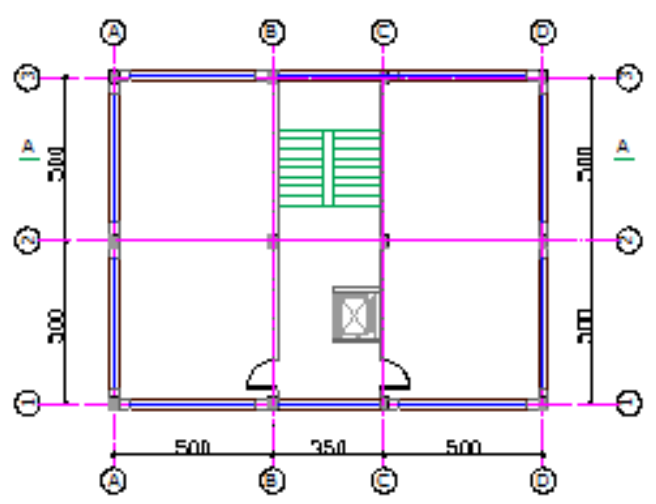

a) $13.8 \mathrm{mx} 10.4 \mathrm{~m}$

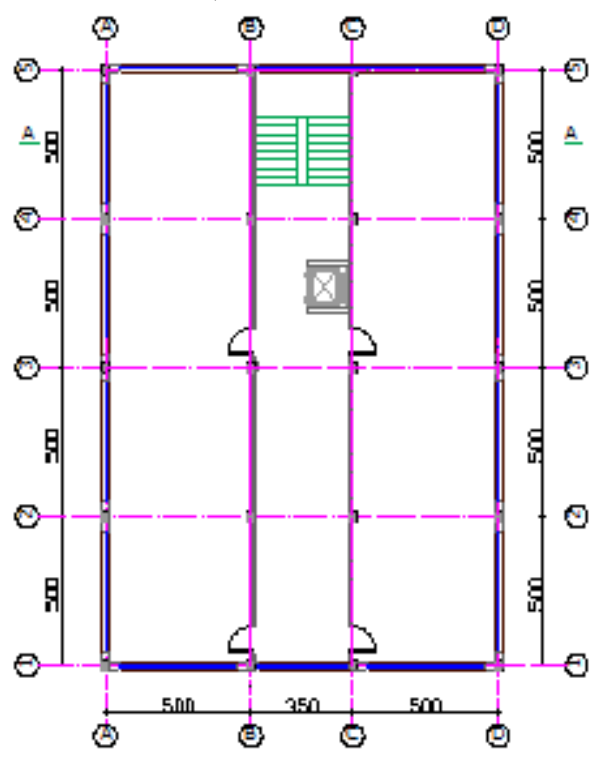

b) $13.8 \mathrm{~m} \times 20.8 \mathrm{~m}$

Fig. 2: Plane of the models: a) 3 floors and 5 floors, b) 5 floors
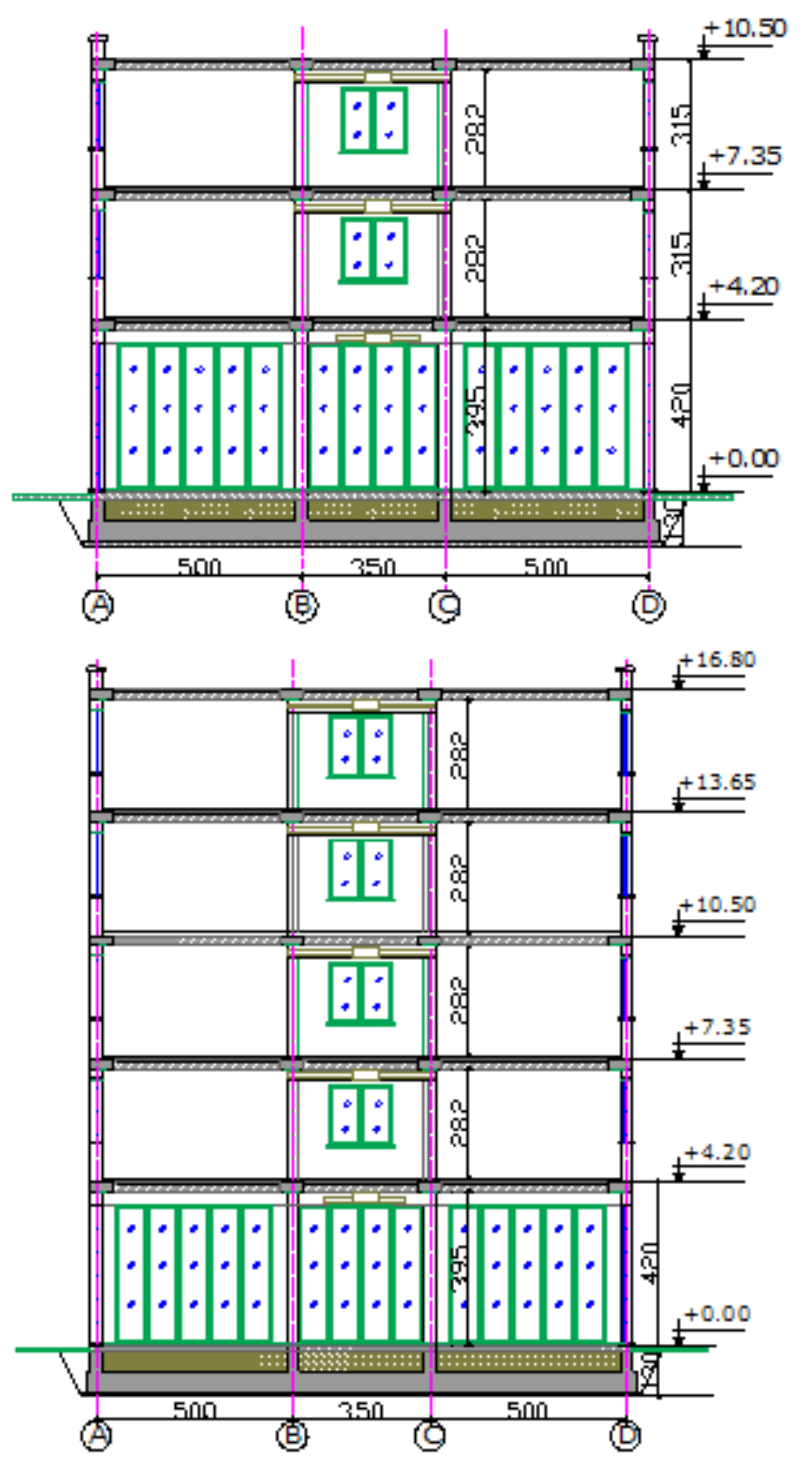

Fig. 3: Section of the model (3 floors and 5 floors)

\section{VERTICAL LOADS AND SEISMIC ACTIONS}

The permanent loads " $G$ " are represented by the self-weight of the structure and additional permanent load uniformly distributed equal to $3 \mathrm{kN} / \mathrm{m} 2$.. In the case of investigated building (which represents an office building - category B, according to [2], the variable-live load in terms of uniformly distributed load amounts to $2 \mathrm{kN} / \mathrm{m} 2$ (EN 1991/Table 6.2). The variable-live loads are, in a seismic design situation, reduced with a factor of $\Psi_{2 \mathrm{i}}=0.3$ (EN 1990/Table A.1.1).

Based on the unit weight of the masonry and plaster a load $9 \mathrm{kN} / \mathrm{ml}$ is considered only over the perimeter beams. The self-weight of the vertical and horizontal elements (columns and beams) are automatically generated in program ETABS [3].

For the design of the building the design response spectrum is used (i.e. elastic response spectrum reduced by the behavior factor $q$ ).

The reference peak ground acceleration amounts to $a_{g R}=$ $0.25 \mathrm{~g}$. The values of the periods $\left(T_{B}, T_{C}, T_{D}\right)$ and of the soil factor $(S)$, which describe the shape of the elastic response 
spectrum, amount to $T_{B}=0.15 \mathrm{~s}, T_{C}=0.5 \mathrm{~s}, T_{D}=2.0 \mathrm{~s}$ and $S=1.2$ (EN 1998-1/Table 3.2). The building is classified as importance class II (EN 1998-1/Table 4.3) and the corresponding importance factor amounts to $\gamma I=1.0(\mathrm{EN}$ $1998-1 / 4.2 .5(5) \mathrm{P})$. Therefore the peak ground acceleration is equal to the reference peak ground acceleration $a_{g}=\gamma I^{*} a_{g R}$ $=0.25 \mathrm{~g}$. Using the equation in EN 1998-1/3.2.2.2 the elastic response spectrum was defined for $5 \%$ damping.

The floor masses and mass moments of inertia are determined according to EN 1998-1/3.4.2. Complete masses resulting from the permanent load (self-weight of the structure $+3 \mathrm{kN} / \mathrm{m} \mathrm{2}$ ) are considered, whereas the masses from the variable-live load are reduced using the factor $\Psi E i=\varphi \cdot \Psi 2 i$. Factor $\Psi_{2} i$ amounts to 0.3 in the case of an office building (EN 1990/Table A.1.1).

\section{STRUCTURAL MODEL}

A three-dimensional structural model is used. The basic characteristics of the model are as follows: All elements are modelled as frame elements. Rigid offset for the interconnecting beams and columns elements are taken into account. All elements are fully fixed in foundation.

Frames are connected together by means of rigid diaphragms (in horizontal plane) at each floor level. The influence of the stairs is studied even for the cases when are modelled the infill walls.

On the cases were the infill walls with hallow bricks is taken into consideration the equivalent struts concept is used [4] and [5]. Different widths are suggested on the literature for the equivalent struts. We have considered $0.25 \mathrm{~d}$ (d- length of the struts) and module of elasticity Ecm $=1.6 \mathrm{GPa}$ and poison coefficient $i \mathrm{n}=0.15$. Here below on figure 4 is presented the $3 \mathrm{~d}$ model in case were the stair case is considered for the frame with embedded beams in to the slab for the two different plan dimensions building.

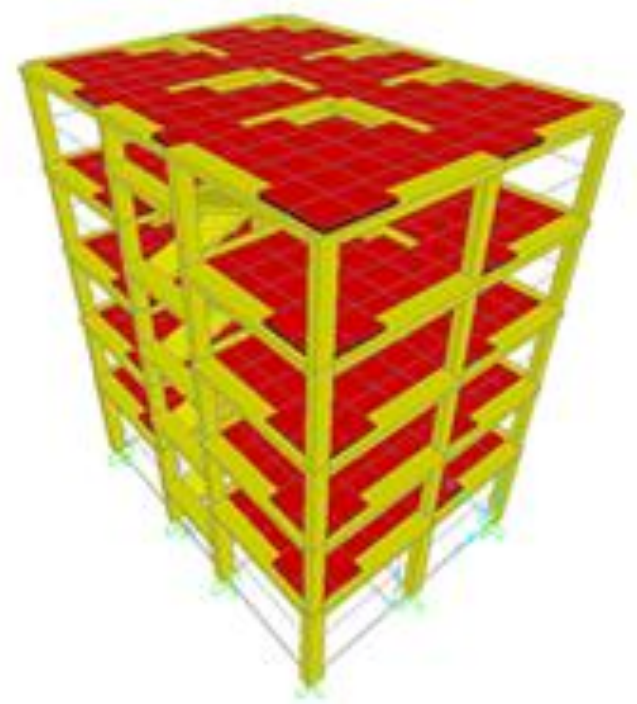

a) $13.8 \mathrm{~m} \times 10.4 \mathrm{~m}$

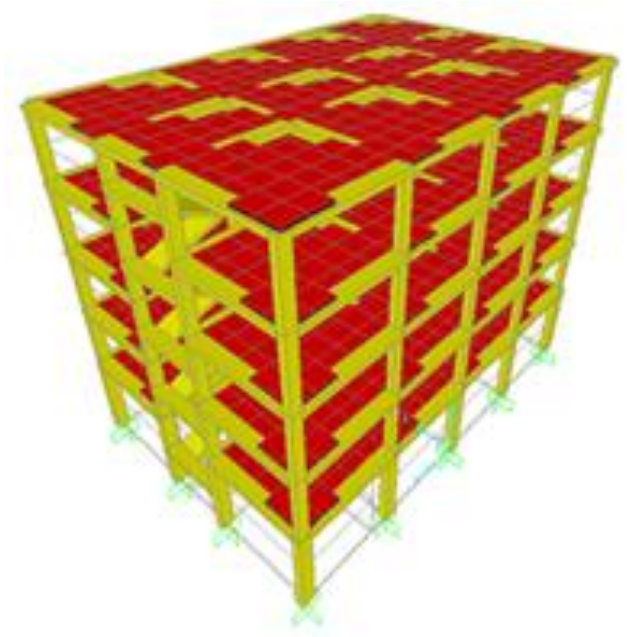

b) $13.8 m \times 20.8 m$

Fig. 4: Mathematical models $3 \mathrm{~d}$. R/C frame with embedded beams in to the slabs

\section{BEHAVIOUR FACTOR DETERMINATIONS}

The behaviour factor $\mathrm{q}$ for each horizontal direction is calculated by equation (EN 1998-1/5.1).

$$
q=q_{0} \times k_{w}
$$

where $q 0$ is the basic value of the behaviour factor and $k_{w}$ is the factor associated with the prevailing failure mode in structural system with walls. In case of frame system according we have: $q=1 \times q 0$ were $q 0^{=} 3^{*} \alpha u / \alpha 1=3^{*} 1.3=3.9$ so: $q=1 \times 3.9=3.9$.

In case of structures with the consideration of infill walls in all the stories over the ground floors this behaviour factor is multiplied by the coefficient 0.8 (important irregularity in elevation).

\section{MODES AND PERIODS}

The first nine modes have been sufficient to satisfy the requirements in EN 1998-1/4.3.3.3(3) (the sum of the effective modal masses amounts to at least $90 \%$ of the total mass).

For each studied cases we have used the definition as below:

FSC- for Frame system classical (normal beams). FSCS- for Frame system classical considering the stairs (normal beams). FSCW- for Frame system classical (normal beams) but considering infill walls over ground floor. FSE- for Frame system classical (embedded beams on the slab). FSES- for Frame system classical considering the stairs (embedded beams on the slab). FSEW- for Frame system classical (embedded beams on the slab) but considering infill walls over ground floor. On the Figure 5 are presented the modes of vibrations. 


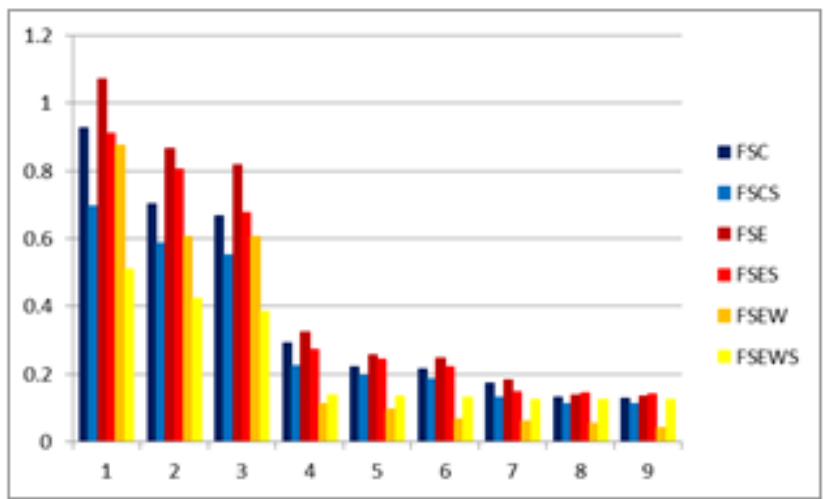

a)

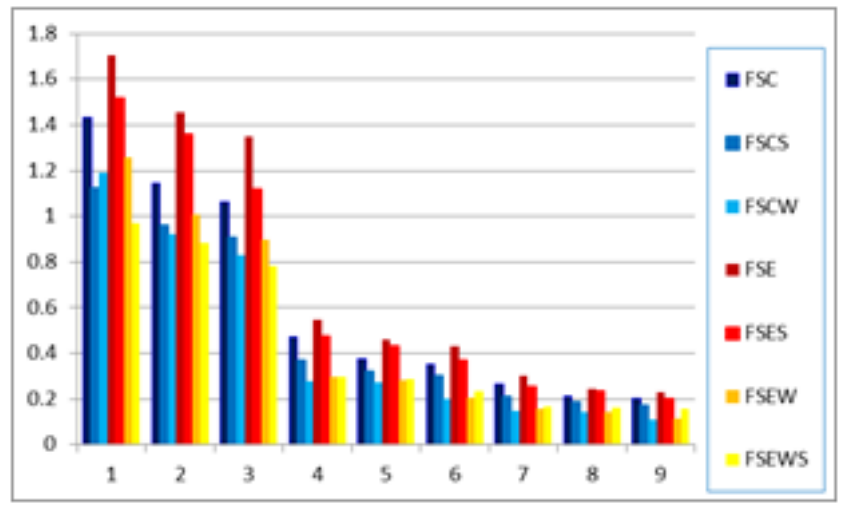

b)

Fig. 5: Modal periods for the models a) with 3 stories and b) with 5 stories

From the above figures we can conclude that the structure with the reinforced concrete frame that has the beams embedded into the slab is very flexible. Even the structure with the normal frame is flexible to. This conclusion can be easy drawn if we refer to conservative expression for modal periods determination as: $\mathbf{T}=\mathbf{0 . 1 \times \mathbf { N }}$, were $\mathrm{N}$ is the floor number. The stairs increase the stiffness of the structure and this reduces the natural periods. Another important characteristic for period of vibration is the fact that in case that the stairs are considered on the mathematical model, the second mode is presenting torsional vibration. Negative effects from this fact on the structural reaction have to be analysed carefully.

\section{DAMAGES LIMITATIONS REQUIREMENTS}

The damage limitation requirement should be verified in terms of the interstorey drift $\left(d_{r}\right)$ (EN 1998-1/4.4.3.2) using equation

$$
\boldsymbol{d}_{\boldsymbol{r}} \cdot \boldsymbol{v} \leq \boldsymbol{\alpha} \cdot \boldsymbol{h}
$$

Story drift $d_{r}$ is evaluated as the difference of the average lateral displacements $d_{S}$ in CM at the top and bottom of the story. The analysed building is classified as importance class II and the corresponding reduction factor $v$ amounts to $0.5, \alpha$ is factor which takes into account the type of the nonstructural elements and their arrangements into the structure. It amounts to 0.005, 0.0075 and 0.01 (EN 19981, equations $4.31,4.32$ and 4.33). For a clear presentation are presented with line the three values of $\alpha$. It can be seen that the most severe drift limit $(\alpha=0.005$, for building having non-structural elements of brittle materials attached to the structure) is exceeded.

First we have presented the comparison between the structures FSC and FSCS. Due to the similarity of results and the limited page number of the articles we are presenting here the results only for the $\mathrm{X}$ - direction.

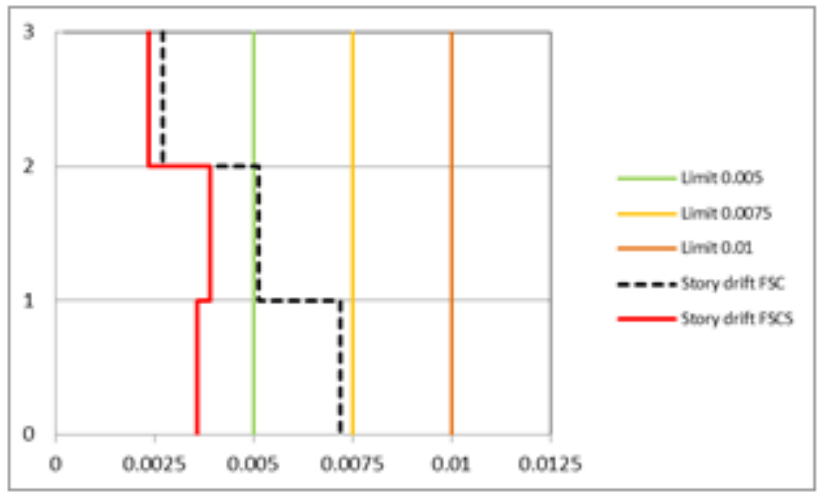

a)

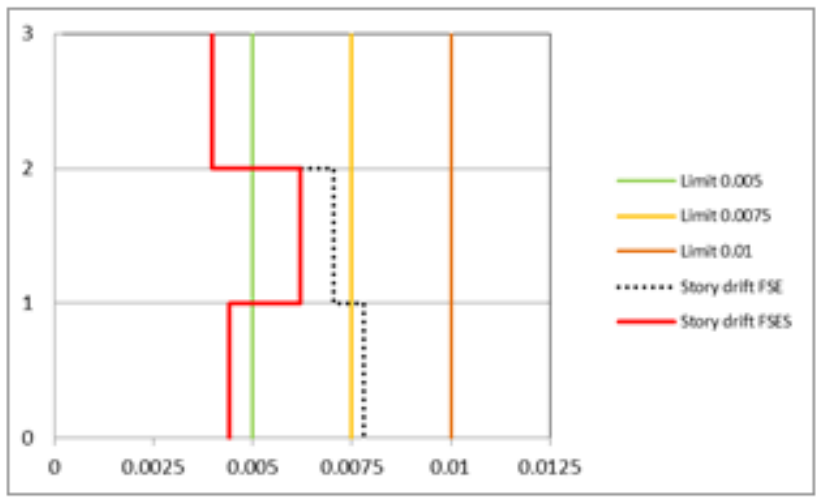

b)

Fig. 6: Comparisons of the models a) FSC, b) FSE for 3 story analytical model

From the Figure 6 we can se that the damage limitation requirement according Eurocode is much difficult to be accommodated for the construction practices in Albania for brittle clay hallow blocks infill walls. The influence of the stairs in story interstorey drifts seems to be positive. This does not mean that their effect is positive for all the structural members. Due to the increased effect of the torsion the vertical elements that are distanced from the stairs are on more severe conditions then from the model that is constructed without stairs.

Even in the cases were taken into consideration the infill walls with hallow bricks (without in ground floor) a slight modification is due to the effect of the stairs. In fact this case brings attention to the phenomenon of soft story created by the absence of the infills in ground floors. This subject is not presented here, he is part of others articles [6].

Below on the Figure 7 are presented the results for the models that have 5 floors. The modification of the periods of vibrations, have influence to the modification of interstorey drift requirements. This influence is much bigger for the 
flexible structures (FSE model). It is not presented here but analysis of the effect of the stairs is done even in case were the structures is uncoupled wall. The influence of stairs on the studied cases is minor and these results are not presented here. When the infill walls are taken into considerations the same comment as for the 3 story are valid.

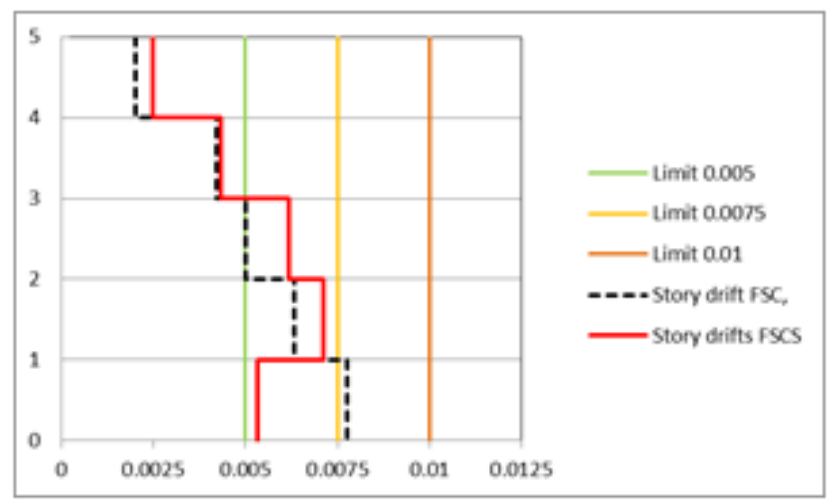

a)

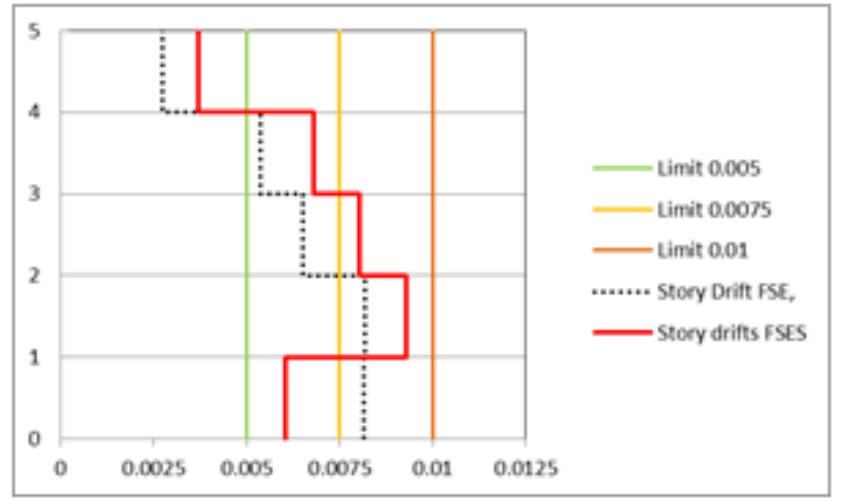

b)

Fig. 7: Comparisons of the models a) FSC, b) FSE for 5 story analytical model

Below on the Figure 8 are presented the results for the models that have 5 floors but with the different plane dimensions of the model. As fare is the vertical element from the stairs the deformations are increased. This is normal reaction, due to the increased torsional effect induced from earthquake inertial forces.

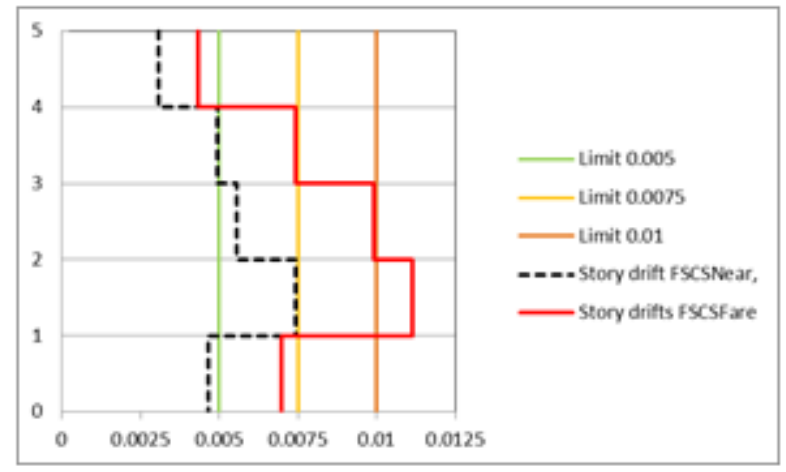

a)

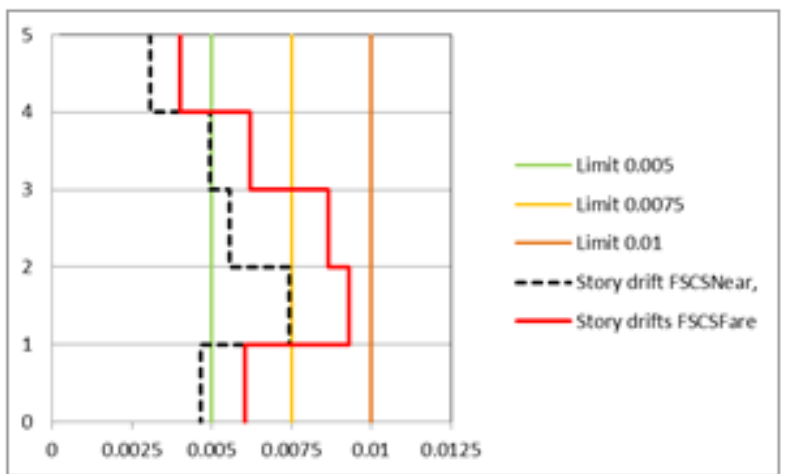

b)

Fig. 8: Comparisons of the 5 story models a) plane dimentions $13.8 \mathrm{mx} 20.8 \mathrm{~m}$ FSC, b) plane dimentions $13.8 \mathrm{mx} 10.4 \mathrm{~m}$

\section{VIII.CONCLUSION}

Based on the linear structural analysis of reinforced concrete frames we conclude:

Frame structures made of reinforced concrete with embedded beam have a higher flexibility than those with the classical frame with the normal beams.

Even the analysed structures have small heights, they both fail to accommodate damages limitation requirement according the Eurocodes if we refer to the construction practices in Albania (infill walls are connected to the frame and are presenting a brittle mode of failure).

Due to the slabs of the stairs and the beams that shortened the column near the stairs, the frame near the stair becomes much stiffer than the others, on $r / c$ frame structures. In this way the modes of vibrations are modified not only to the values, but also to the type of vibrations. In studied cases the second mode of vibration is becoming the torsional when the stairs are modelled.

The influence of stairs in the structure is depended from different factor. Type of stairs, plane of the building and position of stairs, height of the building, structural typologies ect.

The stairs have to be introduced on the mathematical model in order to predict precisely the response of the reinforced concrete frame structures, especially in case of embedded beam frame structures.

\section{ACKNOWLEDGMENT}

The authors wish to thank Professor F. Softa of Tirana Polytechnic University for his support during the elaboration of this study.

\section{REFERENCES}

[1] "Reinforced Concrete Frames and Wall Buildings" by H.Sezen et al. Structural Engineering Reconnaissance of the Kocaeli (Izmit) Turkey Earthquake of August 17 1999. Berkeley: Pacific Earthquake Engineering Research Center, (PEER Report 2000-09), December 2000

[2] Eurocode-8(2004): Design of structures for earthquake resistance" The European Committee for standardization, Final Draft, December 2004

[3] ETABS (2013)", Nonlinear version 13, Extended 3-D analysis of building systems Computers and Structures, Inc.Berkeley, U.S.A 
[4] Conceptual Seismic Design Guidance for New Framed Infill Buildings" Shabnam J. Semnani, Stanford University; Janise E. Rodgers, GeoHazards International; Henry V. Burton, Stanford University

[5] Chopra, A. K., "Dynamics of Structures: Theory and Application to Earthquake Engineering", 2nd Ed, Pearson Prentice Hall, Upper Saddle River, New Jersey, 2007

[6] Seranaj A., Kokona E., Balilaj M., $\square$ Reagimi I ramave fleksibel prej betoni te armuar nen veprimin e forcave sizmike " / Buletini i shkencave teknike, Universiteti Politeknik i Tiranës. Albania. Shkurt 2016 